\title{
Clinco-epidemologial Profile of Organophosphorus Poisoning at Provincial Hospital, Janakpurdham, Nepal
}

\author{
Sanjeet Kumar Jha ${ }^{1 *}$, Divyanshu Jha ${ }^{2}$, Manish Panday ${ }^{1}$, Mahesh Mahaseth ${ }^{1}$
}

${ }^{1}$ Department of Internal Medicine, Provincial Hospital, Janakpur, Province-2, Nepal, ${ }^{2}$ Ex-medical officer, Department of Health, Nepal

\section{ARTICLE INFO}

Article history: Received: 17 March 2021 Revised: 27 April 2021 Accepted: 11 June 2021

*Correspondence: Dr. Sanjeet Kumar Jha Provincial Hospital Janakpur, Nepal

E-mail: jhasanjeet0@gmail.com

Citation:

Jha SK, Jha D, Panday M, Mahaseth M. Clinicoepidemiological Profile of Organophosphorous Poisoning at Provincial Hospital, Janakpurdham, Nepal. MedS. J. Med. Sci. 2021;1(1):37-40

\begin{abstract}
ABSTARCT
INTRODUCTION: Organophosphorus is one of the most common causes of poisoning worldwide. Organophosphorus (OP) poisoning is a major public health problem in Nepal. This study was conducted to observe the epidemiological pattern and mortality in patients with OP poisoning admitted to provincial hospital Janakpurdham, Nepal. MATERIALS AND METHODS: It was a retrospective study. All the consecutive poisoning cases due to op compound admitted through emergency either in the ward or ICU of the provincial hospital from 15 May 2020 to 15 November 2020 included in the study. RESULTS: A total of 160 cases of poisoning were admitted through emergency either in the medical ward or ICU of the provincial hospital. Out Of these $81(51.63 \%)$ was OP poisoning. Among 81 cases $51.85 \%$ were male.70.37 \% of cases were from the young adult group i.e., 15 to 30 years. $38.37 \%$ were housewives. Among all included cases $43.20 \%$ had consumed Methyl parathion (Metacid) followed by Phorate $24.69 \% .55$ $\%$ of total cases were from Dhanusha district followed by Mahottari and Sarlahi. The mortality rate was $14.81 \%$ of total admitted cases, with an average of 5.7 days of hospital stay in the recovered case. CONCLUSIONS: OP poisoning is a major public health problem in province 2. It affects mostly the young age population. Housewives are at more risk of poisoning. The mortality in patients with op poisoning is high even if antidotes are available. Considering the common occurrence and full curability of the condition early arrival to the hospital, timely monitoring, and prompt management may help to reduce mortality. With strict laws on the provision of pesticide availability, the poisoning incidence can be decreased and by proper development of infrastructure and ICU facility mortality can be decreased.
\end{abstract}

KEY WORDS: Organophosphorus, Poisoning, Pesticides.

\section{INTRODUCTION}

Organophosphorus (OP) compounds are used as a pesticide, herbicides, chemical warfare agents and therapeutic agents as ecothiopate for the treatment of glaucoma $[1,2,3,4]$. Poisoning is one of the common causes of admission of young adults in Nepal [5,6]. OP poisoning accounts for about $80 \%$ of the total pesticide-related admissions [7,8].Case fatality is $5-20 \%$ in Asian developing countries like Nepal where agriculture is the main source of total GDP [9]. Poisoning is one of the common means of suicide in Nepal. OP compounds are easily available for purchase in developing countries like Nepal.
The objective of this study was to determine the socio-economic pattern of $\mathrm{OP}$ poisoning and to find the outcome of $\mathrm{OP}$ poisoning in terms of survival and duration of hospital stay.

\footnotetext{
MATERIALS AND METHODS

Study design and setting

A retrospective observational study was conducted at Provincial Hospital, Janakpurdham from 15 May 2020 to 15 November 2020. All the OP poisoning cases admitted to either the department of medicine or Intensive Care Unit of Provincial Hospital included in the study.
} 


\section{Participants and study procedures}

Data was collected from medical records of patients with poisoning. There were 160 cases of poisoning admitted through the emergency department of provincial hospital. Only 81 out of these fulfilled the inclusion criteria and were included in the analysis. Patients below the age of 15 years and patients poisoned with other compounds were excluded. The diagnosis was made based on a definite history of ingestion of OP compound and clinical features suggestive of $\mathrm{OP}$ compounds. Most of the time patient-party brought the container. If the compound consumed is unknown, patients were screened through an atropine challenge test. Patients who tested

\section{RESULTS}

Out of 160 cases, only 81 (50.63\%) had OP poisoning, confirmed either by definite history or container or clinical features and atropine challenge test. OP poisoning was attributed main to Methyl parathion $35(43.20 \%)$ followed by Phorate 20 (24.69\%) and Chlorpyrifos 15 (18.52\%) Table-1.

\begin{tabular}{|c|c|c|}
\hline Op compound & $\begin{array}{l}\text { Number of } \\
\text { patients }\end{array}$ & $\begin{array}{l}\text { Percentage } \\
(\%)\end{array}$ \\
\hline Methyl Parathion & 35 & 43.21 \\
\hline Phorate & 20 & 24.69 \\
\hline Chlorpyriphos & 15 & 18.52 \\
\hline Dimethoates & 5 & 6.17 \\
\hline Dichlorvos & 6 & 7.41 \\
\hline
\end{tabular}

Among 81 cases of OP poisoning, 42 (51.85\%) were male and 39 (48.15\%) were female. $70.37 \%$ of total OP poisoning cases were between 15 to 30 years of age. In this age group, there were 28 males and 29 females which were almost equal in numbers. Most of the cases were housewives 31 (38.27\%) followed by labor $20(24.70 \%)$, student 13 $(16.02 \%)$, farmers $8(9.88 \%)$ and others $9(11.13 \%)$ Most of the OP poisoning cases admitted were from Dhanusha, Mahottari and Sarlahi district. Accordingly 44 (55\%) were from Dhanusha, 26 (32.5\%) from Mahottari, 5 (6.25\%) from Sarlahi and rest $5(6.25 \%)$ were from other districts and places (Table-2). positive were classified as organophosphorus poisoned. Resources for cholinesterase levels were not available at the hospital. The characteristic manifestation of OP compounds was noted and for other compounds, the diagnosis was solely dependent on information provided by the container or patients or their relatives.

\section{Statistical consideration}

The data collected was entered in MS Excel and statistical analysis was done. Univariate analysis was carried by calculating the frequency and percentage. Furthermore, mean, median and standard deviation were calculated.

\begin{tabular}{lll}
\hline \multicolumn{2}{l}{$\begin{array}{l}\text { Table 2l Socio-demographic characteristic of study } \\
\text { subjects (N=81) }\end{array}$} & \multicolumn{2}{l}{ Total Number } \\
\hline Characteristics & Category & $42(51.9 \%)$ \\
\cline { 2 - 3 } Gender & Male & $39(48.1 \%)$ \\
Age in year & Female & $57(70.4 \%)$ \\
& $15-30$ & $15(18.5 \%)$ \\
& $31-45$ & $4(4.9 \%)$ \\
& $46-60$ & $5(6.2 \%)$ \\
& $>60$ & $44(54.3 \%)$ \\
& Dhanusha & $26(32.1 \%)$ \\
& Mahottari & $5(6.2 \%)$ \\
& Sarlahi & $5(6.2 \%)$ \\
& Others & $20(24.7 \%)$ \\
& Labor & $8(9.9 \%)$ \\
& Farmer & $13(16.0 \%)$ \\
& Students & $31(38.3 \%)$ \\
& Housewife & $9(11.1 \%)$ \\
& Others & \\
& & \\
& &
\end{tabular}

\begin{tabular}{llll}
\hline \multicolumn{3}{l}{ Table3 | Outcome of hospital stay } & \\
\hline $\begin{array}{l}\text { Age } \\
\text { (in years) }\end{array}$ & Recovered & Referred & Expired \\
\hline $15-30$ & 44 & 3 & 10 \\
$31-45$ & 12 & 1 & 2 \\
$46-60$ & 4 & 0 & 0 \\
$>60$ & 5 & 0 & 0 \\
Total & $65(80.25 \%)$ & $4(4.94 \%)$ & $12(12.81 \%)$ \\
\hline
\end{tabular}


Among 81 OP poisoning cases, 65 (80.25\%) recovered while 12 (14.81\%) expired who were mainly from the young age group of 15 to 30 years and 4 (4.94\%) were referred, either on patient party request or due to unavailability of intensive care (Table-3). Death among the age group of $15-30$ years contributed $83.33 \%$ (10) of total death that occurred i.e. 12 . Also $66.67 \%$ (8) of the total death was of females (Figure 1).

\section{DISCUSSION}

The retrospective study underlines that OP compounds are the most common pesticides used for self-poisoning [10,11]. Different studies on OP poisoning show female predominance in South Asian countries $[6,7,8,9,10]$. This study revealed a higher incidence of poisoning in males $(51.85 \%)$ with a ratio of $1.08: 1$. Based on their

\section{CONCLUSIONS}

Organophosphorus poisoning is a major public health problem in Nepal. It affects mainly young population. Females especially housewives, who has to deal with many responsibilities are at higher risk of OP poisoning. There should be strict law regarding buying, distributing and marketing, so that poisoning incidence and mortality can be decreased. This

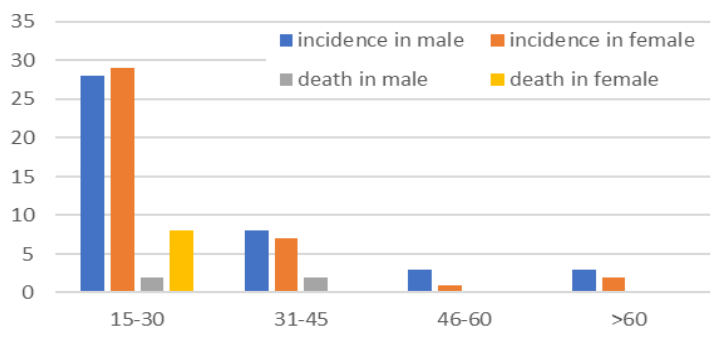

Figure 1। Incidence and mortality by age and gender

occupation, housewives $(38.27 \%)$ were the most affected, followed by labor, students and others. This finding varies from other similar studies $[6,11,12,13,14,15]$. In this study, the mortality rate of $14.8 \%$, is in accordance with the results of various studies done in Nepal, with a mortality rate ranging from 7.4 to $13 \%[13,14,15,16]$.

study highlights the need to establish a poison information center to provide systematic awareness about the OP poisoning to young adults and housewives. It can be achieved by systematic studies on OP poisoning and psychological aspects of young adults from lower economic classes.

\section{ADDITIONAL INFORMATION AND DECLARATIONS} Funding: Self

Competing Interests: The authors declare no competing interests.

Author Contributions: Concept and design: S.K. J, M.P. and M.M; Statistical analysis: S.K.J and D.J; writing of the

\section{REFERENCES}

1. Eddleston $\mathrm{M}$, Buckley NA, Eyer $\mathrm{P}$ a Eddleston $\mathrm{M}$, Buckley NA, Eyer P and Dawson AH. Management of acute organophosphorus pesticide poisoning. The Lancet. 2008;371:587-607.

2. Joshi S, Biswas B and Malla G. Management of organophosphorus poisoning. Update in anaesthesia.pg.1-5.

3. Eddleston M. patterns and problems of deliberate self-poisoning in the developing world. Q J MED. 200:93:715. manuscript: M.P, M.M and D.J; revision and editing of the manuscript: S.K.J and D.J; All authors have contributed to literature review, analysis, interpretation of result, and revision, and all have read and agreed with the content of the manuscript

Data Availability: Data will be available upon request to corresponding authors after valid reason.
4. Hoek w Van Der, Konradsen F and Athukorala K. Pesticide poisoning a major health problem in Sri Lanka. Soc Sci Med. 1998; 46:495-504.

5. Rehiman S, Lohani SP and Bhattarai MD. Correlation of serum cholinesterase level, clinical score at presentation and severity of organophosphorus poisoning. JNMA. 2008; 47(170):47-52.

6. Paudyal BP. Organophosphorus poisoning. JNMA. 2008; 47(172):251-8. 
7. Walker BR, Colledge NR, Ralston $\mathrm{SH}$ et al. Poisoning: Organophosphorus insecticide and nerve agent. Davidson's principles of medicine. Reed Elsevier India Private limited. 2014; 9:22022.

8. Jamil H. Acute poisoning. A review of 1900 cases JPMA. 1900; 40:131-3.

9. Nepal in figures. Central bureau of statistics. 2010.

10. Bharati U, Shrestha JB and Sharma M. Study of Acute poisoning in Nepal Medical College Teaching Hospital. NMCJ. July 2000-January 2001;2:283-85.

11. Prasad PN, Karki P. Poisoning cases at TUTH Emergency -A one-year review. Journal of the Institute of Medicine. 1997;19:18-24.

12. Pathak U, Chhetri PK, Dhungel S et al. Retrospective study of poisoning cases admitted in Nepal Medical College Teaching Hospital. Nepal Medical College Journal. 2002;3(2):101-105.

13. Kar SM, Timsinha S, Agrawal P. An Epidemiological study of Organophosphorus Poisoning at Manipal
Teaching Hospital, Pokhara, Nepal. J Indian Acad Forensic Med. 32(2):108-9.

14. Khadka SB, Ale SB. A study of poisoning cases in emergency Kathmandu Medical College Teaching Hospital. KUMJ. 2005;3: 388-91.

15. Kafle KK, Gyawali K -Organophosphorus commonest poisoning agent. Journal of Institute of Medicine. 1992;14:228-33.

16. Thunga $G$, Sam KG, Khera $K$ et al. Evaluation of incidence, clinical characteristics and management in Organophosphorus poisoning patients in a tertiary care hospital. Journal of Toxicology and Environmental Health Sciences. 2010; 2:73-74.

17. Bhattarai MD, Singh DL, Chalise BS et al. A case report and overview of organophosphate poisoning. Kathmandu University Medical Journal. 2006;4:100104. 